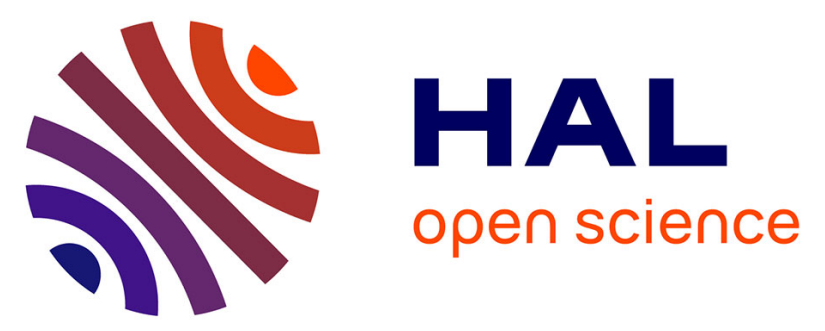

\title{
Unusual heme binding properties of the dissimilative nitrate respiration regulator, a bacterial nitric oxide sensor.
}

Serena Rinaldo, Nicoletta Castiglione, Giorgio Giardina, Manuela Caruso, Alessandro Arcovito, Stefano Della Longa, Paola d'Angelo, Francesca

Cutruzzolà

\section{To cite this version:}

Serena Rinaldo, Nicoletta Castiglione, Giorgio Giardina, Manuela Caruso, Alessandro Arcovito, et al.. Unusual heme binding properties of the dissimilative nitrate respiration regulator, a bacterial nitric oxide sensor.. Antioxidants and Redox Signaling, 2012, 17 (9), pp.1178-89. 10.1089/ars.2011.4226 . pasteur-00952196

\section{HAL Id: pasteur-00952196 https://hal-riip.archives-ouvertes.fr/pasteur-00952196}

Submitted on 26 Feb 2014

HAL is a multi-disciplinary open access archive for the deposit and dissemination of scientific research documents, whether they are published or not. The documents may come from teaching and research institutions in France or abroad, or from public or private research centers.
L'archive ouverte pluridisciplinaire HAL, est destinée au dépôt et à la diffusion de documents scientifiques de niveau recherche, publiés ou non, émanant des établissements d'enseignement et de recherche français ou étrangers, des laboratoires publics ou privés. 


\title{
Unusual Heme Binding Properties of the Dissimilative Nitrate Respiration Regulator, a Bacterial Nitric Oxide Sensor
}

\author{
Serena Rinaldo,,2,* Nicoletta Castiglione,,2,* Giorgio Giardina, ${ }^{1,2}$ Manuela Caruso,,2 \\ Alessandro Arcovito, ${ }^{3}$ Stefano della Longa, ${ }^{4}$ Paola D'Angelo, ${ }^{5}$ and Francesca Cutruzzolà ${ }^{1,2}$
}

\begin{abstract}
Aims: In the opportunistic pathogen Pseudomonas aeruginosa, nitric oxide (NO) triggers the respiration of nitrate (denitrification), thus allowing survival in chronic infection sites as a microaerobic-anaerobic biofilm. The NO-dependent induction of denitrification is mediated by the dissimilative nitrate respiration regulator (DNR), a transcription factor forming a stable complex with heme, which is required to sense the physiological messenger (i.e., NO). The molecular details of NO sensing in DNR and, more in general, in this class of sensors are largely unknown, and a study aimed at integrating microbiology and biochemistry is needed. Results: Here we present a comprehensive study, including in vivo results and spectroscopy, kinetics, and protein engineering, that demonstrates the direct involvement of a histidine residue in heme iron coordination. Moreover, a peculiar phenomenon of ligand switching around heme iron, which hampers the identification of the second heme axial ligand, is also suggested. These results indicate that DNR is characterized by a remarkable flexibility in solution, as observed for other cAMP receptor protein/fumarate and nitrate reductase regulators (CRP-FNR) to which DNR belongs. Innovation: The present work represents one of the few studies focused on the biochemistry of NO sensing by bacterial transcriptional regulators. The data presented demonstrate that structural plasticity of DNR is crucial for the sensing activity and confers to the protein unusual heme binding properties. Conclusions: Protein flexibility and dynamics is a key structural feature essential to explain the evolutionary success and adaptability of CRP-FNR, and may represent a common strategy employed by heme-based redox sensors, which presents features deeply different from those of canonical hemeproteins. Antioxid. Redox Signal. 17, 1178-1189.
\end{abstract}

\section{Introduction}

T HE CAMP RECEPTOR protein/fumarate and nitrate reductase regulator (CRP-FNR) superfamily of regulators includes proteins involved in a wide range of regulatory decisions in bacteria, such as oxygen, nitric oxide (NO), and redox state sensing, thanks to their ability to bind various cofactors $(17,27,45)$. The adaptability of these bacterial sensors has been recently pointed out as a reason to explain their evolutionary success (16). These regulators are usually homodimers, each monomer being formed by three domains (35): (i) an N-terminal-sensing domain with the typical fold of the cAMP-binding domain of CRP; (ii) a dimerization $\alpha$-helix recruited to form the dimer interface; and (iii) a C-terminal DNA-binding domain with a helix-turn-helix (HTH) motif. In these transcription factors, activation is triggered by binding of a signal molecule, which induces the conformational change from an OFF conformation (unable to bind DNA) to an ON conformation (able to bind DNA) $(4,31,39)$. In the latter conformation, the two recognition helices of the HTH motif are in the correct position to bind the cognate DNA sequence by interaction with the major groove. On the contrary, when these regulators are in the inactive form (OFF conformation), the DNA-binding domain of each monomer can change its orientation dramatically by rotating around the connection with the dimerization helix (called hinge).

\footnotetext{
${ }^{1}$ Istituto Pasteur Fondazione Cenci Bolognetti and ${ }^{2}$ Department of Biochemical Sciences "A. Rossi Fanelli," Sapienza University of Rome, Rome, Italy.

${ }^{3}$ Istituto di Biochimica e Biochimica Clinica, Università Cattolica del Sacro Cuore, Rome, Italy.

${ }^{4}$ Dipartimento di Medicina Sperimentale, Università dell'Aquila, L'Aquila, Italy.

${ }^{5}$ Dipartimento di Chimica, Sapienza University of Rome, Rome, Italy.

*These authors contributed equally to this work.
} 


\section{Innovation}

The present work represents one of the few studies aimed at characterizing the biochemistry of nitric oxide (NO) sensing from transcriptional regulators; among $\mathrm{NO}$ sensors involved in denitrification, the dissimilative nitrate respiration regulator (DNR) is the sole regulator whose sensing activity has been analyzed both in vitro and in vivo. The outcome of this study underlines how structural flexibility of the cAMP receptor protein/fumarate and nitrate reductase regulator (CRP-FNR) class of regulators represents a novel strategy to interact with the heme as redox cofactor; this plasticity is crucial for sensing activity by DNR and confers to the protein unusual properties in heme binding. All the evidences reported clearly indicate and confirm the existence of an emerging class of heme-based redox sensors, which presents features deeply different from those of canonical hemeproteins.

In the human pathogen Pseudomonas aeruginosa, the transcription factor dissimilatory nitrate respiration regulator (DNR) induces, under low oxygen tension and in the presence of $\mathrm{N}$-oxides, the expression of the alternative respiratory pathway of denitrification $(1,41)$. This pathway allows the bacterium to survive in the anaerobic-microaerobic environment typical of the multicellular community (biofilm) formed in the infected host and to scavenge the NO produced by the host defense (52). In pathological conditions, such as those found in the pulmonary epithelium of cystic fibrosis (CF) patients, the expression of denitrification genes (and thus their activation by DNR) is required for swarming and virulence (47) and more in general to maintain the aggressive mucoid phenotype (18). Thus, since the antibiotics commonly used in the treatment of CF are much less effective against the bacterium growing in the anaerobic biofilm, the development of new drugs able to interfere with P. aeruginosa anaerobic metabolism may represent a promising strategy for a more effective treatment of chronic CF lung infections (18).

It has been recently shown that recombinant $P$. aeruginosa DNR is able to transactivate a target promoter in an NOdependent fashion also in Escherichia coli, a nondenitrifier (5); moreover, in vivo results show that DNR requires also heme biosynthesis to fulfill its biological role (5). DNR forms a stable complex with heme, suggesting an involvement of this cofactor in the NO-sensing mechanism (13). Spectral and kinetic characterization on the purified DNR protein reconstituted with heme $b$ suggests that heme iron is six-coordinate in the reduced form but switches to a five-coordinate form upon $\mathrm{NO}$ binding (13). To date, how heme controls the NO-dependent response of DNR is still unknown.

A structural insight into DNR was obtained by solving the structure of a truncated version of the protein (hereinafter N152STOP), lacking the entire DNA-binding domain (13) and more recently, the structure of the full-length DNR (12) in the OFF conformation, both in the apo form. These data indicate that DNR is extremely flexible and that activation may involve a large conformational change from the OFF conformation, experimentally determined, to the ON conformation, modeled from the N152STOP structure $(12,13)$. This reorganization leads to the formation of a hydrophobic pocket be- tween the sensing domain and the dimerization helix where the heme may bind.

Based on these results, we have recently proposed (12) that effective transcriptional regulation requires NO binding to the heme-containing DNR. A detailed characterization of hemeDNR complex is therefore crucial to fully understand the mechanism of action. In this article we present a comprehensive study, carried out both in vivo and in vitro, by combining beta-galactosidase activity assays, protein engineering, $X$-ray absorption fine structure (XAFS) and ultraviolet-visible (UV-Vis) spectroscopy and kinetics, which allowed us to shed light on the mechanism of heme iron coordination and NO sensing. We suggest that the structural plasticity of $P$. aeruginosa DNR, strongly supported by the data presented here, is a common feature of heme-based redox sensors, an emerging class of hemeproteins.

\section{Results}

\section{Expression and purification of heme-containing DNR}

As previously published (13), a remarkable fraction of heme-containing DNR is obtained when the protein is expressed in the presence of hemin in the growth medium; a small amount of hemeprotein is always found, even when DNR is expressed in the absence of any supplement (data not shown). To understand whether the spectroscopic properties of the in vitro heme-reconstituted DNR (13) are comparable with those of heme-containing DNR expressed in the presence of hemin, we analyzed different derivatives of the latter (partially purified) protein (Fig. 1). The UV-Vis spectra show features of a six-coordinate hemeprotein both in the ferric and in the ferrous state (Fig. 1A, dotted and bold line, respectively), as observed for the in vitro heme-reconstituted DNR protein (hereinafter DNR); moreover and more interestingly, the protein seems to form a five-coordinate NO-bound derivative (Fig. 1B), as previously observed for this NO sensor (13). The same results were obtained by analyzing the derivatives of partially purified DNR expressed in the presence of the heme precursor $\delta$-aminolevulinic acid (data not shown).

\section{Identification of the heme axial ligands by XAFS spectroscopy}

Since our recent hypothesis (12) implies that the NOdependent activation of DNR occurs through a heme-induced conformational change, a detailed study of the features of the heme-protein complex has been carried out.

Here we report the characterization of the heme iron environment in DNR by XAFS spectroscopy in the low-energy range (the X-ray absorption near edge structure or XANES regime) and in the high-energy range (the extended XAFS or EXAFS regime). These are powerful techniques to measure the structure of metal sites in solution (51). The Fe-K edge XANES spectra of the ferric (dotted line) and ferrous (solid line) DNR are shown in Figure 2A; to assign the axial coordination of the heme iron, the derivative XANES spectrum of ferric DNR (Fig. 2B) was compared with several ferric heme models and hemeproteins (Fig. 2C). The energy of the main derivative peak of ferric DNR (at about $7126 \mathrm{eV}$ ) is $1-2 \mathrm{eV}$ lower than all the ferric models, but it is aligned, and the highest similarity is obtained with the spectrum of formally ferric neuroglobin $(\mathrm{Ngb})$. Indeed, ferric $\mathrm{Ngb}$ is rapidly photo- 


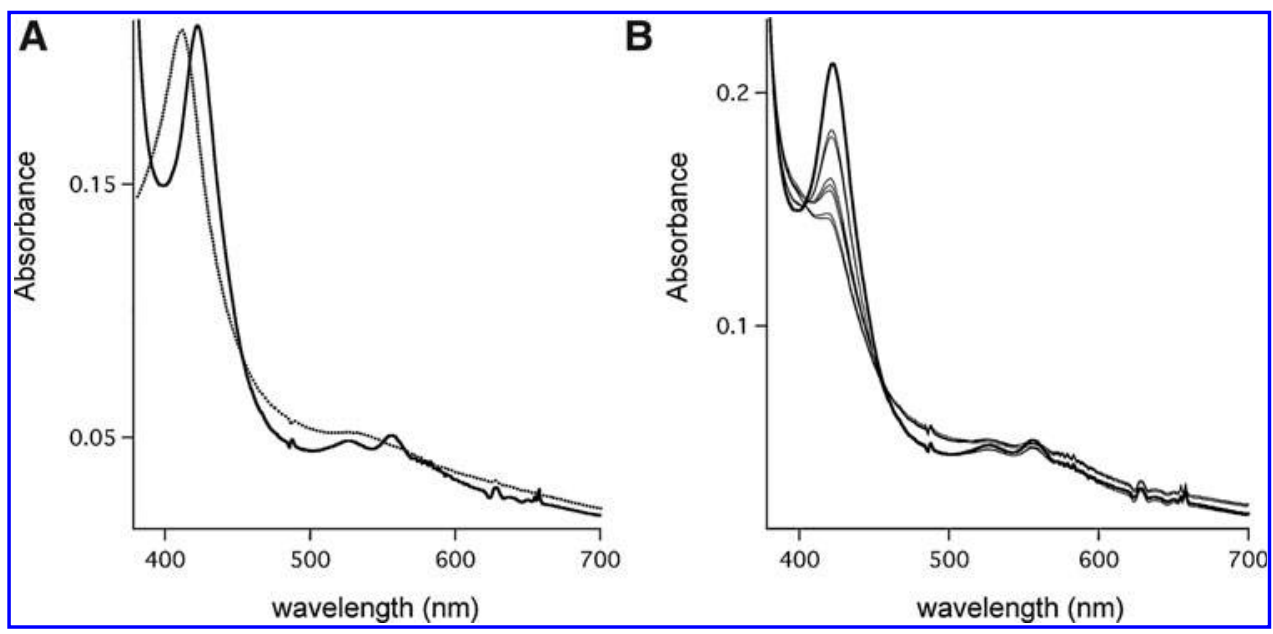

FIG. 1. Spectra of partially purified heme-containing dissimilatory nitrate respiration regulator (DNR), expressed in the presence of hemin. (A) $\mathrm{Fe}^{3+}$ (dotted line) and $\mathrm{Fe}^{2+}$ (bold line) derivatives. The $\mathrm{Fe}^{2+}$ derivative was obtained in the presence of $1 \mathrm{mM}$ dithionite under anaerobic conditions. (B) $\mathrm{Fe}^{2+}$ derivative (bold line) has been incubated with excess of NO in a gastight tonometer and the corresponding spectra were collected (thin gray lines). Similarly to the in vitro heme-reconstituted protein, addition of nitric oxide (NO) to the $\mathrm{Fe}^{2+}$ protein yields a species with a Soret band shifted below $400 \mathrm{~nm}$ (the absorbance of the excess of dithionite in this region of the spectrum hampers precise peak identification) and a broad band in the visible region, typical of a five-coordinate NO-bound heme.

reduced under X-ray irradiation, and thus it is a formally ferric species (3). Since Ngb is a typical example of a low-spin heme iron with bis-histidine coordination in both oxidation states, in the absence of further available models for axial coordination (for example, from tyrosine), the spectroscopic signature of DNR is compatible with two histidine residues as heme axial ligands. The energy alignment between photoreduced $\mathrm{Ngb}$ and ferric DNR strongly suggests that also DNR is photoreduced under X-ray irradiation; thus, from now on, we will refer to ferric DNR as formally ferric. The Fe-K edge XANES spectrum of ferrous DNR is red-shifted by $<1 \mathrm{eV}$; it also exhibits a shoulder at the absorption edge (peak at $7117 \mathrm{eV}$ in the derivative spectrum; Fig. 2B) that is absent in the spectrum of the ferric one and suggests that a fraction of the ferrous heme is four-coordinate (8) (see also legend to Fig. 2 and Supplementary Fig. S1; Supplementary Data are available online at www.liebertonline.com/ars).

The Fe-K edge XANES spectrum was measured also for the ferrous DNR-NO derivative (Fig. 3). The spectrum of DNR$\mathrm{NO}$ is more similar to that of the five-coordinate model compound $\mathrm{Fe}(\mathrm{II})$-tetraphenylporphyrin-NO (TPP-NO) than to that of nitrosyl-myoglobin ( $\mathrm{MbNO}$, bearing a six-coordinate Fe-heme). This result strengthens the idea that the NO derivative of DNR is five-coordinate, as previously hypothesized on the basis of the UV-Vis spectrum (13).

\section{In vivo activity of His mutants of DNR}

The results obtained by X-ray absorption spectroscopy on wild-type DNR suggest that two histidines are involved in the coordination of the heme iron. To identify which histidine(s) binds the heme, all histidine residues present in DNR were mutated to alanines (eight single mutants: H7A, H51A, H139A, H155A, H167A H187A, H200A, and H209A; one double mutant: H14A/H15A); the position of the individual histidine residues in DNR is depicted in the model of the ON conformation shown in Figure 4B.
To assess the effect of these substitutions on the NO-sensing and transcriptional activity in vivo, the DNR-dependent activation of the $P$. aeruginosa nor promoter was measured in E. coli under anaerobic conditions in the presence of $10 \mu \mathrm{M} \mathrm{NO}$ (Fig. 5, gray bars) and compared to that of the wild-type protein (5); control experiments were carried out under anaerobic conditions without NO (Fig. 5, white bars). The results show that three out of nine mutants display a wild-type-like NO-dependent transcriptional activity (i.e., H14A/H15A, H155A, and H167A) while the remaining ones (H7A, H51A, H139A, H187A, H200A, and H209A) show a significant decrease in activity. The N152STOP mutant, which lacks the entire DNA-binding domain, was previously shown to be inactive in the same assay (5). Among the mutants that are transcriptionally inactive in vivo, the effect of the H139A and H187A mutations could be explained with an impaired interaction with the heme group, being both residues localized nearby the putative heme-binding pocket (Fig. 4B) identified on the basis of structural data (12).

\section{Spectroscopic characterization of DNR mutants}

All the histidine mutants were expressed, purified, and reconstituted with hemin. The optical absorption spectra of the ferric and ferrous species were determined together with the $\mathrm{Fe}^{2+}-\mathrm{CO}$ and $\mathrm{Fe}^{2+}-\mathrm{NO}$ bound derivatives. The absorption peaks of the various derivatives, compared to those of the wild-type DNR (see also Fig. 6 A) are summarized in Table 1. Surprisingly, the spectral properties of the mutants are not dramatically different from those of the wild-type protein. The spectra of the ferrous form suggest that the heme iron is predominantly six-coordinate, whereas the $\mathrm{CO}$ - and $\mathrm{NO}$ derivatives appear to be six- and five-coordinate, respectively (Table 1). Only the H187A, one of the mutants unable to respond to NO in vivo, shows significant changes in the spectrum of the ferric and ferrous derivatives, both in the Soret and in the visible region (Fig. 6B). The spectra of H187A slightly change with time (Table 1 and Fig. 6B), suggesting a 


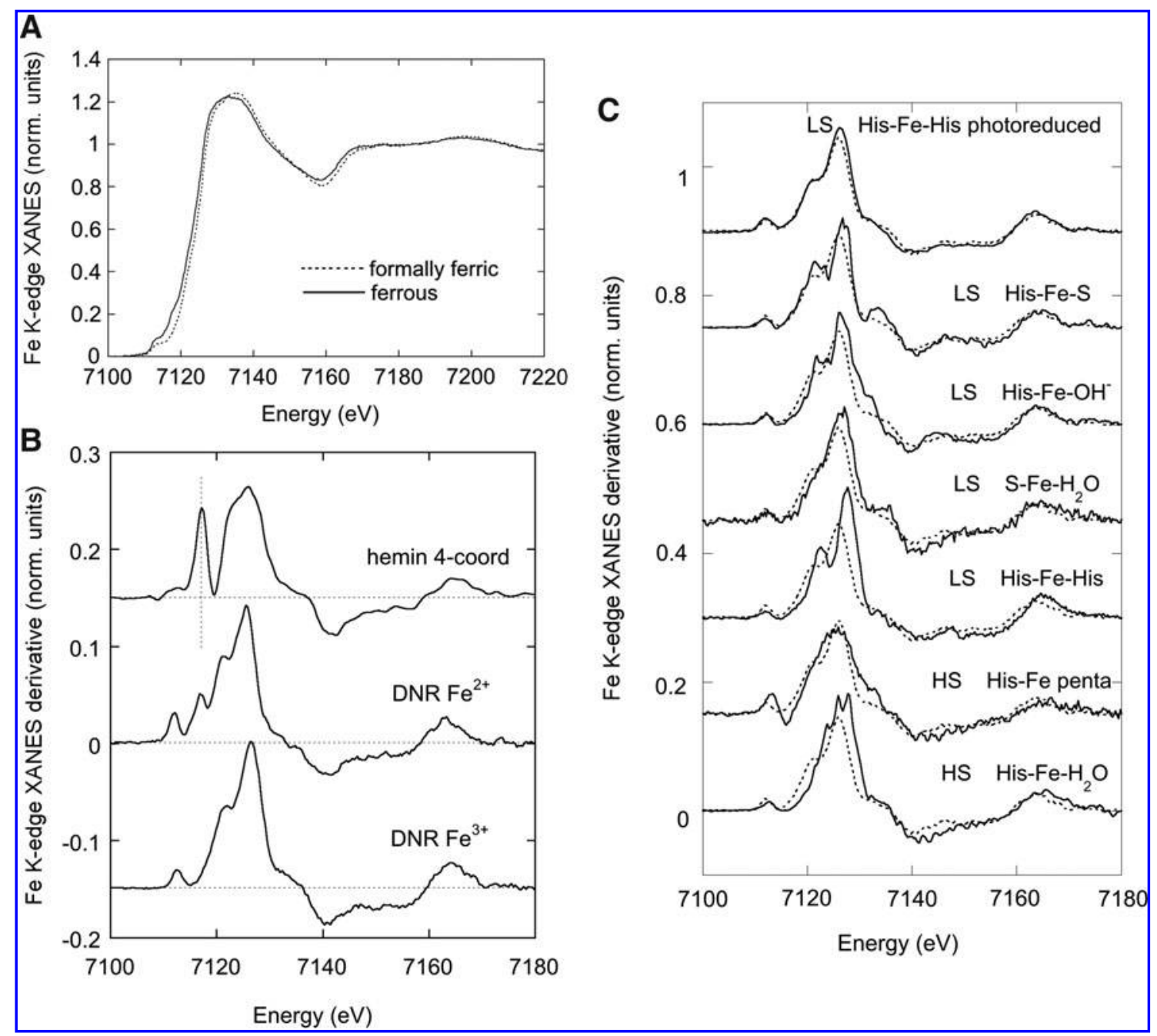

FIG. 2. XANES fingerprints of heme ligands. (A) Fe K-edge X-ray absorption near edge structure (XANES) spectra of DNR in the putative ferric form (dashed line) and in the ferrous one (continous line). (B) The XANES derivative spectra of putative ferric wild-type DNR and ferrous wild-type DNR are compared with the spectrum of four-coordinate hemin. In DNR, a residual $0.5 \mathrm{eV}$ edge red-shift, between the main peak at 7125.8 in ferrous DNR and $7126.3 \mathrm{eV}$ in the formally ferric one, is explained by residual charge density in the chemically reduced form, and/or by the effect of change in the symmetry of the Fe-heme site due to (partial) ligand dissociation, as observed in myoglobin (7). (C) The XANES derivative spectrum of formally ferric DNR (dotted curve) is compared with various high-spin (HS) and low-spin (LS) coordination models of the heme iron in heme models and hemeproteins (black solid lines). From top to bottom: neuroglobin [His-Fe(III)-His, this derivative is rapidly photoreduced under X-ray beam], cytochrome c [His-Fe(III)-Met]; alcaline LS met-myoglobin [His$\mathrm{Fe}(\mathrm{III})-\mathrm{OH}^{-}$], cytochrome $\mathrm{P} 450$ [Cys-Fe(III)- $\mathrm{H}_{2} \mathrm{O}$ ]; Fe(III)-tetraphenylporphiryn-bis(imidazole) [imidazole-Fe(III)-imidazole]; 1,2 metil-imidazole and hemin dissolved in sodium dodecyl sulfate micelles [imidazole-Fe(III) five-coordinate]; and acid aquomet-myoglobin, His-Fe(III)- $\mathrm{H}_{2} \mathrm{O}$.

(slow) conformational rearrangement of the protein around the heme. The only other DNR variant that, as expected, shows UV-Vis spectroscopic properties significantly different from the wild-type is the N152STOP mutant (Table 1 and Fig. 6C). Surprisingly, the H139A mutant does not display spectroscopic properties significantly different from those of the wild-type protein (Table 1).

As already reported for other heme-based sensors, the UVVis analysis may not be sensitive enough to probe the hemeiron environment contrary to circular dichroism (CD) spectra in the visible region $(21,26)$; the CD signal arises from the interaction of the electric transition moment of the heme with the nearby aromatic side chains of the protein but, in the case of a dimer, a major contribution comes from the coupling with the partner heme molecule (20). CD spectra were collected for all histidine mutants in the $350-480 \mathrm{~nm}$ region. A negative splitting of the Cotton effect is observed in wild-type DNR and in all His mutants (data not shown): remarkably, both the H187A and the N152STOP mutant show significant differences in the CD spectrum with respect to the wild type (Fig. 7). The larger amplitude of the splitting of the Cotton effect, which indicates a stronger coupling between the two heme molecules, is indicative of a less flexible and more compact structure with respect to wild-type DNR.

\section{Reactivity with ligands of DNR mutants}

The spectra of the ferrous form of the His mutants suggest that the heme iron is predominantly six-coordinate (Table 1). 


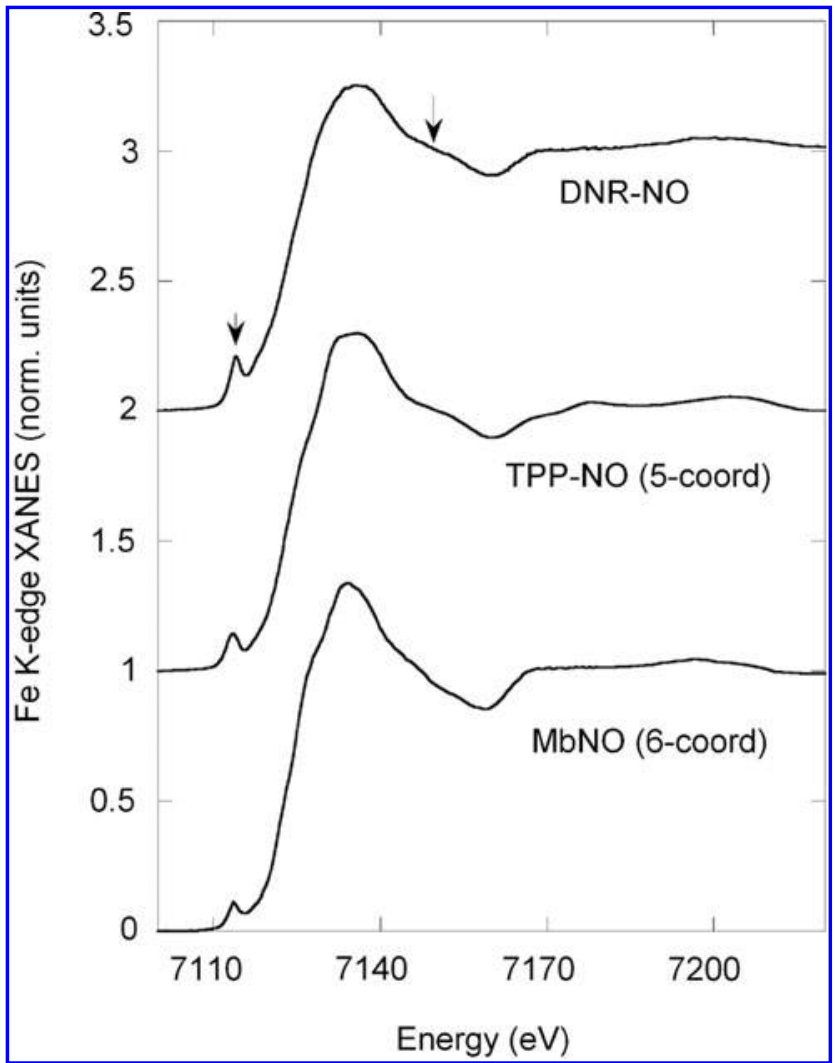

FIG. 3. XANES spectrum of the NO-bound species of DNR and reference compounds. The Fe K-edge XANES spectrum of ferrous DNR-NO (upper curve) is compared with the five-coordinate $\mathrm{Fe}(\mathrm{II})$-tetraphenylporphyrin ([TPP]-NO) derivative (intermediate curve) and the hexa-coordinate nitrosyl-myoglobin (MbNO) derivative (lower curve). The pre-edge peak intensity at $7114 \mathrm{eV}$ and the feature emerging at $7150 \mathrm{eV}$ (shown by the arrows) suggest that the heme iron of the DNR form is five-coordinate.

To probe the heme environment in the ferrous protein, laser photolysis experiments were carried out starting from the $\mathrm{Fe}^{2+} \mathrm{CO}$ complex under anaerobic conditions (Table 2). In wild-type DNR, two fast CO-dependent and a slower COindependent kinetic processes were observed. Analysis of the absorbance changes show that the faster $\mathrm{CO}$-dependent phase accounts for $50 \%$ of the total amplitude, while the remaining $50 \%$ is given by the sum of the second CO-dependent phase and by the CO-independent process (see also Supplementary Fig. S2). A possible interpretation of the heterogeneity of CO re-binding is that each monomer of DNR reacts differently: one monomer show a CO-dependent phase as reported for other hemeproteins like myoglobin (14), while the other monomer requires re-binding of a proximal ligand. The same kinetic profile is observed in all mutants analyzed; notably, in the H187A mutant the three processes are significantly slowed down, further suggesting that the heme environment is changed in this protein (Table 2).

Given that DNR is an NO sensor, the reactivity of the ferrous protein with $\mathrm{NO}$ is physiologically relevant. Therefore, the $\mathrm{NO}$ dissociation rate constant was determined for all His mutants starting from the $\mathrm{Fe}^{2+}-\mathrm{NO}$ complex in the presence of dithionite and $\mathrm{CO}$. The rate constant for $\mathrm{NO}$ dissociation was found to be slow (about $2 \times 10^{-4} \mathrm{~s}^{-1}$ ), close to that of the wildtype protein (13) and in the range typical of other proteins containing a ferrous $b$-type heme (25). Only in the case of the H187A and N152STOP mutants the NO dissociation process is significantly slower than the wild-type protein, 3 and 10 -fold $\left(0.8\right.$ and $\left.0.2 \times 10^{-4} \mathrm{~s}^{-1}\right)$, respectively (Supplementary Fig. S3).

To fully characterize the reactivity with $\mathrm{NO}$ for the H187A and N152STOP mutants the rate of NO binding was measured by mixing the reduced protein with NO (88-175 $\mu \mathrm{M}$, after mixing [a.m.]) in the stopped-flow. The NO binding kinetics was found to be similar to that observed for wild-type DNR. In the range explored, combination was shown to be independent of NO concentration and biphasic, with each phase being $\sim 50 \%$ of the total amplitude expected for the transition. The values obtained for the two kinetic phases are $12.8( \pm 0.4)$ and $0.8( \pm 0.02) \mathrm{s}^{-1}$ for N152STOP and $15( \pm 0.4)$ and $0.9( \pm 0.03) \mathrm{s}^{-1}$ for H187A (see Supplementary Fig. S4). As expected for other six-coordinate hemeproteins (44) and wildtype DNR (13), in both mutants NO binding is rate-limited presumably by the dissociation of a heme ligand.

\section{Spectroscopic characterization of selected heme pocket DNR double mutants}

To better understand the structural determinants of DNRheme interaction, two double mutants in residues located in the putative heme-binding pocket (H139A/H187A and H167A/H187A) have been produced and the corresponding proteins analyzed spectroscopically.

As reported in Figure 8, only the H167A/H187A double mutant show spectroscopic features deeply altered with respect to the H187A single mutant (Fig. 6B); the appearance of a prominent peak at $370 \mathrm{~nm}$ suggests an increased heterogeneity of the sample, in which the heme is supposed to be mainly four-coordinate (or weakly coordinated to water molecules) (Fig. 8A). On the other hand, the H139A/H187A mutant spectra are not significantly different from those of H187A, suggesting that His139 does not participate in heme coordination, despite the fact that its position in the pocket is in principle compatible with heme binding (Fig. 4B).

\section{Discussion}

$P$. aeruginosa DNR is a bacterial NO sensor involved in the activation of the alternative energy metabolism of denitrification when the oxygen tension drops. The current model of DNR activation requires NO binding to the heme and conversion to the biologically active state of the protein. Involvement of heme in the activity of DNR was previously shown both in vitro (13) and in vivo (5). Recombinant DNR is expressed in E. coli as a heme-containing protein; the spectroscopic properties of this holoprotein are comparable with those of the in vitro heme-reconstituted DNR protein (employed in the present study) (Fig. 1).

In this study we report novel experimental evidence that allows us to propose that the heme-DNR complex has unusual properties relevant for the activity of this bacterial NO sensor. The first outcome of this study is that the XANES spectrum of the heme iron in formally ferric DNR has been found to be highly compatible with that of a low-spin sixcoordinate bis-histidine species. Moreover, the XANES spectrum of ferrous DNR in the presence of NO shows the highest 
FIG. 4. Three-dimensional structure of the dimer of Pseudomonas aeruginosa DNR. (A) The structure and domain organization of the full-length DNR (PDB id: 3DKW) (12) is shown on the right. The model of the same protein in the active (ON) conformation is depicted on the left. The latter model is a chimera in which the first 140 $\mathrm{N}$-terminal residues belong to the crystal structure of the N152STOP mutant Protein Data Bank (PDB) id: 2Z69) (13), while the last 87 residues (the DNA-binding domain) are modeled on the structure of cAMP receptor protein (PDB id: 1RUN). One monomer is depicted in gray while the second is depicted according to the legend in the figure. (B) The position of the His residues in the model of the active conformation of DNR (see above) is shown. The His mutants that were found to have reduced activity in vivo are labeled in bold.

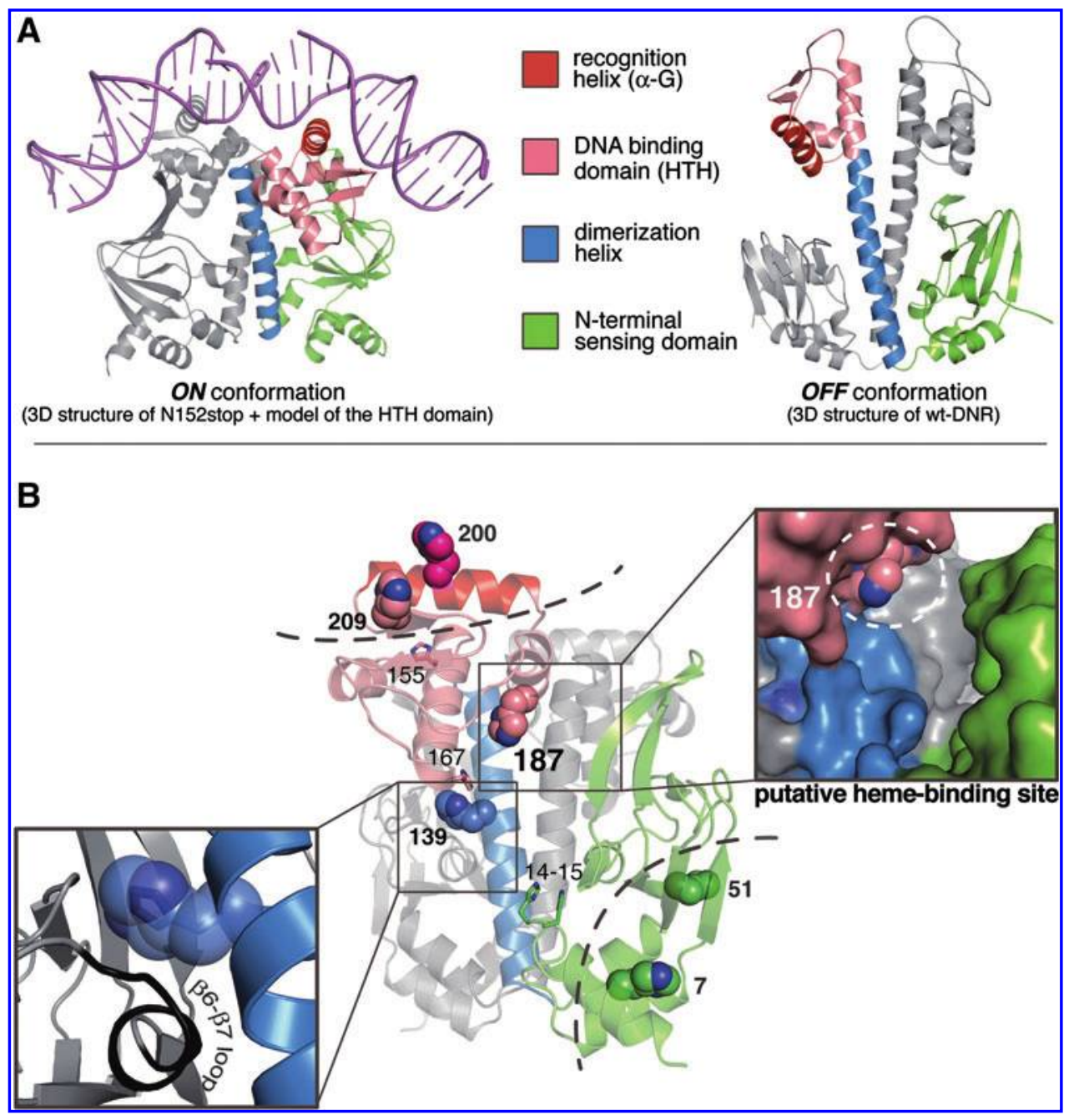

similarity with that of the five-coordinate species used as a model, in agreement with the data on other heme-based NO sensors (15). In these hemeproteins, the biologically active form is the five-coordinate NO complex and ligand binding to the heme triggers rapid dissociation of a protein residue (often a His), thus allowing the conformational change necessary for activation.

To gain mechanistic insight into DNR activation, we have mutated the His residues of DNR into alanines, obtaining eight single mutants and one double mutant. These mutants were studied both in vivo, to understand if the substitution of a histidine putatively involved in coordinating the heme iron jeopardizes the NO-dependent transcriptional activation by DNR, and in vitro, to evaluate the effect of mutation on the heme environment.

In vivo studies indicate that several His mutants are inactive (Fig. 5); to rationalize the results, these mutants can be divided into three groups.

The first group encompass His residues (His200 and His209) located in (or nearby) the main DNA recognition helix $\alpha-G(5,9,12)$ (Fig. 4). The complete inability of the H200A mutant to bind the $P$. aeruginosa nor promoter (Fig. 5) can be explained with the loss of a positive charge in the region involved in DNA recognition. Whereas mutation of His200 into alanine abolishes the activity of DNR, its substitution with lysine (H200K mutant) does not alter the ability to transactivate the target promoter (in an NO-dependent fashion) (see Supplementary Fig. S5), suggesting that the positive charge in this position is crucial for the interaction of DNR with DNA. In agreement with this interpretation, a histidine residue or a positively charged aminoacid (such as arginine) is found in this position among DNR-like proteins from Pseudomonas stutzeri. Moreover, despite the lower overall sequence similarity, also the CRP protein from E. coli presents a lysine in the same position, which was shown to be located in the protein/DNA interface (38). In DNR, the other histidine residue (His209) located nearby the same recognition helix $\alpha$ G shows a residual $30 \%$ activity in vivo; this may suggest that, compared to His200, substitution of His209 destabilizes the DNR/DNA interaction to a lower extent.

The second group of inactivating mutations (H7A and H51A) cannot be easily interpreted; they are not located in the putative heme-binding pocket, even though they fall in the Nterminal sensory domain (Fig. 4). It is not excluded that both residues might be involved in the interaction with RNA polymerase, taking into account that they are positioned within regions involved in the protein/RNA polymerase interaction in homologous transcription factors $(32,12,28)$.

The third group of His mutants (H139A and H187A) showing reduced activity in vivo likely identify residues 


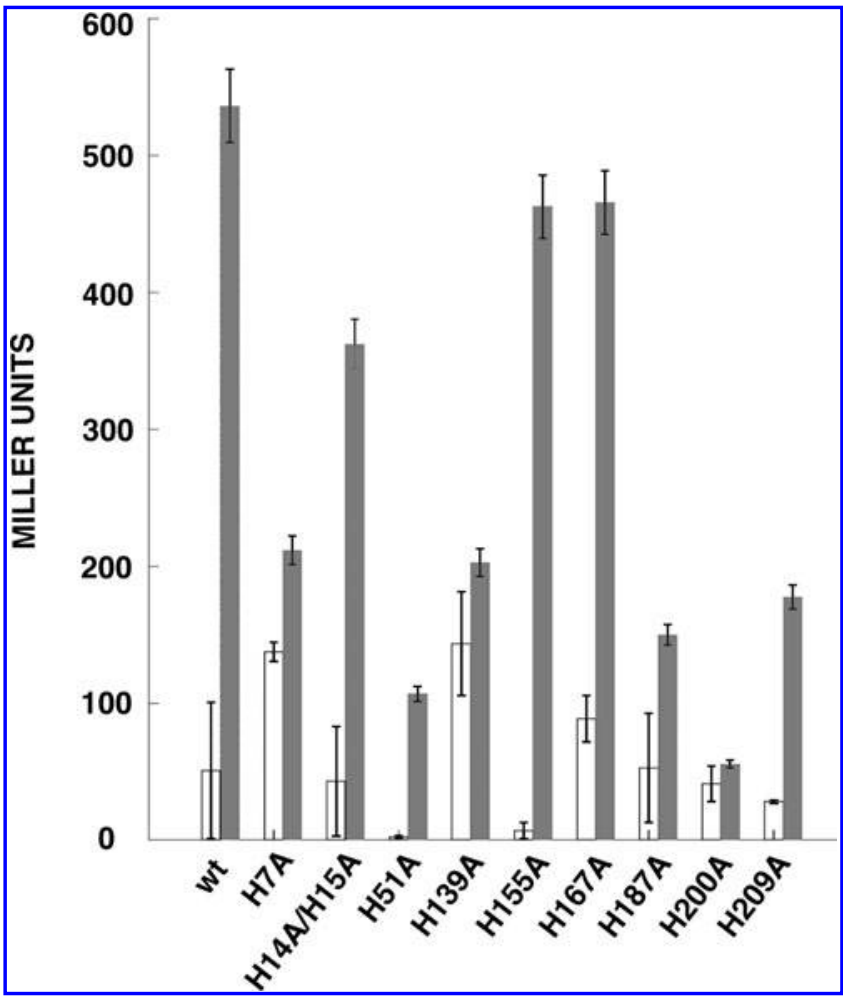

FIG. 5. NO-dependent activation of the P. aeruginosa nor promoter by DNR site-directed mutants. The DNR mutants have been expressed constitutively in the TOP10 E. coli strain together with the pRS-NOR plasmid (carrying the $P$. aeruginosa nor promoter). The $\beta$-galactosidase activity was measured under anaerobic conditions in the absence (white bars) and in the presence of $10 \mu \mathrm{M}$ NO (gray bars), as previously described for the wild-type protein (5). Activity is reported in Miller Units (36).

involved in heme binding, since these aminoacids are positioned in the putative heme-binding pocket (Fig. 4).

Based on several results (spectroscopic and kinetic), we assign His187 as one of the axial ligands of the heme iron in DNR. First of all, H187A is the only histidine mutant showing significant changes in the UV-Vis spectrum with respect to the wild-type protein. In agreement with this result, the truncated
N152STOP mutant, lacking the entire DNA-binding domain and thus five His residues (including His187), (13) also has different spectroscopic features (both UV-VIS and CD) from wild-type DNR. These results establish that the residues belonging to the HTH domain of DNR (and in particular His187) contribute to the formation of the correct heme-binding environment and thus to ensure proper activity of the regulator. This interpretation is supported by the observation that the release of the signal molecule $\mathrm{NO}$ (monitored by following the kinetics of NO dissociation) is slowed down in H187A and, more significantly, in the N152STOP mutant.

The importance of a His residue in the topological position of H187 is also confirmed by its conservation in several orthologs, including the closely related NO sensor DnrD from $P$. stutzeri (48). Remarkably, comparison of the aminoacid sequence of DNR with that of the NNR regulator from Paracoccus denitrificans, previously shown to have a heme-dependent activity in vivo (30), shows that this is the only conserved His residue between the two proteins (data not shown).

As mentioned before, the other His residue located in the heme-binding pocket of DNR is His139. The H139A single mutant is unable to respond to $\mathrm{NO}$ in vivo, but its spectroscopic features are not significantly different from those of wild-type DNR. However, if His139 is really an axial ligand of the heme iron, as initially hypothesized, mutation of both His139 and His187 into alanine should deeply interfere with proper heme binding. Beyond all expectations, the H139A/ H187A double mutant presents spectroscopic features similar to those of the H187A single mutant, confirming that His139 is not directly involved in heme binding. An alternative hypothesis, yet to be demonstrated, is that mutation of His139, a residue located in a region clearly involved in the allosteric regulation of the CRP-FNR proteins (Fig. 4) (24), may interfere with the conformational transition (OFF/ON) that involves the dimerization helix (where His139 is located) and the sensing domain, thus resulting in the observed decrease in the NO-dependent transcriptional activity.

Therefore, whereas the identification of His187 as one of the heme ligands is out of any doubt, at this stage the unequivocal identification of the second heme axial ligand in DNR by in vitro studies is not easy; a precise assignment of heme ligands in this regulator appears to be hampered by DNR flexibility, which may allow dynamic exchange of heme ligands (see below). UV-Vis spectra suggest that this phenomenon

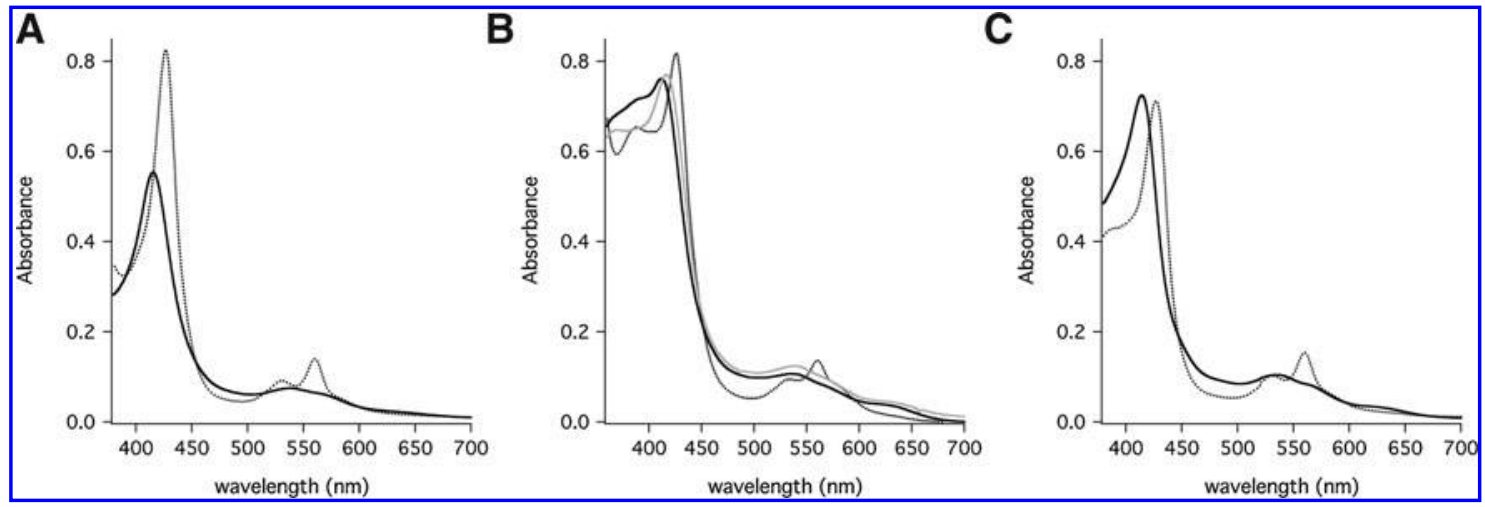

FIG. 6. Spectral properties of wild-type and mutants DNR proteins. Optical absorption spectra of the Fe ${ }^{3+}($ black line) and $\mathrm{Fe}^{2+}$ (dotted line) derivatives of (A) wild-type, (B) H187A, and (C) N152STOP DNR proteins. The Fe ${ }^{3+}$ derivative of the H187A protein after the rearrangement is also reported (B, gray line). 
Table 1. Spectral Properties of $\mathrm{THe} \mathrm{Fe}^{3+}, \mathrm{Fe}^{2+}, \mathrm{Fe}^{2+}-\mathrm{CO}$, and $\mathrm{Fe}^{2+}-\mathrm{NO}$ Bound Derivatives of the DNR Proteins Analyzed in the Present Study

\begin{tabular}{|c|c|c|c|c|c|c|c|c|c|c|c|}
\hline \multirow{2}{*}{$\begin{array}{l}\text { Protein } \\
\text { Wild type }\end{array}$} & \multicolumn{2}{|l|}{$\mathrm{Fe}^{3+}(\mathrm{nm})$} & \multicolumn{3}{|c|}{$\mathrm{Fe}^{2+}(\mathrm{nm})$} & \multicolumn{3}{|c|}{$\mathrm{Fe}^{2+} \mathrm{CO}(\mathrm{nm})$} & \multicolumn{3}{|c|}{$\mathrm{Fe}^{2+} \mathrm{NO}(\mathrm{nm})$} \\
\hline & 417 & 538 & 427 & 530 & 559 & 421 & 541 & 568 & 389 & 537 & 563 \\
\hline N152STOP & 412 & 534 & 427 & 531 & 560 & 421 & 541 & 568 & 387 & 540 & 564 \\
\hline H7A & 417 & 538 & 427 & 530 & 560 & 422 & 542 & 571 & 388 & 538 & 563 \\
\hline H14A/H15A & 415 & 538 & 426 & 531 & 559 & 421 & 539 & 568 & 388 & 538 & 561 \\
\hline $\mathrm{H} 51 \mathrm{~A}$ & 414 & 537 & 427 & 530 & 560 & 420 & 540 & 568 & 388 & 537 & 562 \\
\hline H139A & 415 & 539 & 426 & 530 & 559 & 420 & 540 & 568 & 389 & 537 & 560 \\
\hline H155A & 415 & 538 & 425 & 530 & 559 & 421 & 540 & 568 & 388 & 537 & 561 \\
\hline H167A & 416 & 537 & 427 & 530 & 560 & 421 & 541 & 569 & 389 & 537 & 563 \\
\hline H187A & $412(390)^{\mathrm{a}} 416(360)^{\mathrm{a}, \mathrm{b}}$ & 536 & $426(390)^{\mathrm{a}}$ & 532 & $560(584)^{\mathrm{a}}$ & 421 & 541 & 569 & 386 & 539 & 561 \\
\hline H200A & 415 & 538 & 427 & 530 & 560 & 420 & 538 & 566 & 388 & 541 & 561 \\
\hline H209A & 415 & 537 & 426 & 530 & 560 & 420 & 540 & 568 & & & \\
\hline
\end{tabular}

${ }^{a}$ Values in parentheses refer to shoulders observed in the UV-Vis spectrum.

${ }^{\mathrm{b}}$ These peaks have been observed 3-4 days after reconstitution with heme.

occurs likely in the H187A mutant and possibly in other mutant(s) where the putative second heme axial ligand has been changed into alanine.

Structural flexibility is crucial to control the activity of these regulators, as already demonstrated for DNR (12) and for several other CRP-FNR, by structural and biochemical analysis $(11,46,49)$. Moreover, a peculiar structural flexibility is characteristic of heme-based sensor proteins and confers them atypical biochemical properties $(12,13,19)$, so that mutation/ deletion of key residues will not necessarily result in dramatic spectral changes. This behavior implies that ligand switching involving protein residues nearby the heme may occur, as

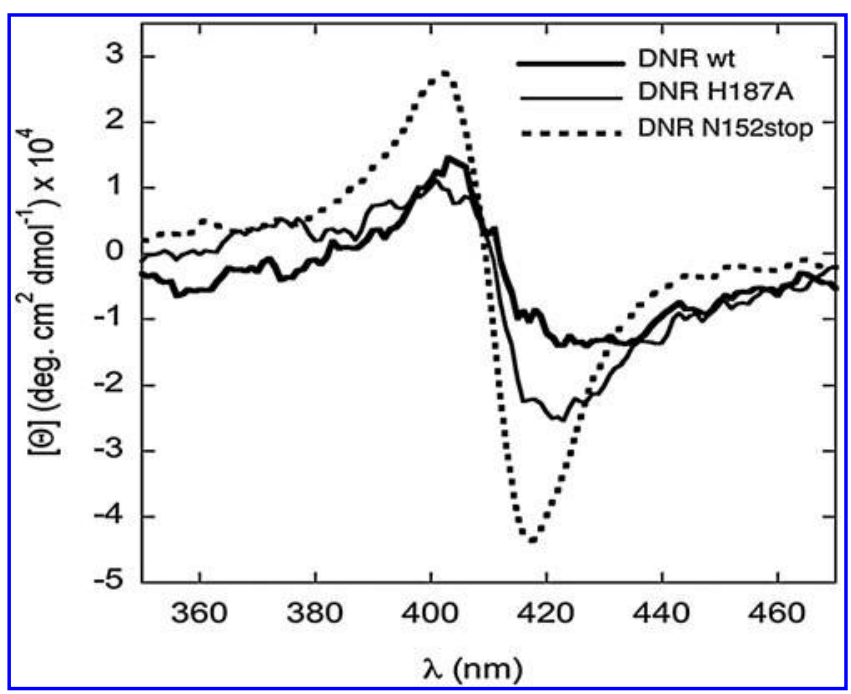

FIG. 7. Circular dichroism (CD) spectra in the Soret region. The spectra of wild-type DNR and of the H187A and N152STOP mutants are shown. Differences in the split amplitude $(\Delta \varepsilon)$ or in the positive or negative peak of the CD spectra of DNR wild-type compared to the mutants reflect a local difference in the structure of the heme-binding site and/or of the relative position of the two heme molecules in the dimer. The spectrum of the wild-type DNR protein displays a peak at $404 \mathrm{~nm}$ and a trough at $425 \mathrm{~nm}$ with $\Delta \varepsilon=-8$. On the other hand, H187A (thin line) shows a more intense trough at $421 \mathrm{~nm}$ and N152STOP (dotted line) shows the major deviation from the wild-type displaying a $\Delta \varepsilon$ of -22 . well documented in the literature $(19,23)$. Thus, taking into account the unusual spectroscopic properties reported in the present study for DNR mutants, we strongly suggest that this same behavior would apply to this protein.

The ligand switch phenomenon due to DNR flexibility is unmasked by looking at the reactivity with $\mathrm{CO}$. Since binding of $\mathrm{CO}$ to the ferrous heme thermodynamically favors a hexacoordinate complex with the proximal ligand bound, re-binding of $\mathrm{CO}$ to $\mathrm{Fe}^{2+}$-heme after photolysis allows investigation of the reactivity of the proximal residue with iron. In general, the lack of the native proximal residue or the presence of a non-native substitute alters the $\mathrm{CO}$ re-binding kinetic profile (23). After photolysis, all DNR His mutants show a kinetic profile close to that of the wild-type protein, except the H187A mutant that displays the lowest rates of $\mathrm{CO}$ re-binding. Therefore, the results obtained on the H187A mutant suggest that the $\mathrm{CO}$ rebinding experiments have unmasked the presence of an alternative endogenous ligand in the absence of His187; since this switch occurs in a fraction of molecules, we can trap and directly observe the ligand switch.

The alternative proximal ligand in the H187A single mutant was identified by mutating both His187 and the neighboring His167 (H167A/H187A mutant): lack of both residues strongly hampers correct heme binding. Since the two residues (His187 and His167) are near to each other and located on the same side of the putative heme-binding pocket (Fig. $4 \mathrm{~B})$, it is unlikely that they may bind to the heme iron as proximal and distal residues, respectively. A plausible hypothesis is that, in the single H187A mutant, the side chain of His167 may partially coordinate the heme iron in place of the missing His187, thus explaining the properties of the H187A protein; this indicates that in this mutant a ligand switching is really taking place, mainly thanks to the His167 residue.

Our results strongly suggest that, after mutation of a His residue, the protein is able to provide alternative ligand(s) to maintain the hexacoordinate heme state. In agreement with this hypothesis, all mutants tested behave as hexacoordinate hemoproteins, as suggested by UV-Vis spectroscopy and confirmed by the kinetics of $\mathrm{NO}$ binding to $\mathrm{Fe}^{2+}$. In the latter experiment, the NO binding rate does not depend on NO concentration (over the range explored), indicating that in these mutants dissociation of a protein residue limits $\mathrm{NO}$ binding, as previously shown for wild-type DNR and as 
Table 2. Carbon Monoxide Re-Binding Rates to DNR $\mathrm{Fe}^{2+}$ Derivatives Upon Laser Photolysis

\begin{tabular}{lccc}
\hline Protein & $\begin{array}{c}\mathrm{k}_{1} \times 10^{-4} \\
\left(s^{-1} \mathrm{m \textrm {M } ^ { - 1 }}\right)\end{array}$ & $\begin{array}{c}\mathrm{k}_{2} \times 10^{-4} \\
\left(s^{-1} \mathrm{mM}^{-1}\right)\end{array}$ & $\begin{array}{c}\mathrm{k}_{3} \times 10^{-3} \\
\left(\mathrm{~s}^{-1}\right)\end{array}$ \\
\hline Wild type & $2.31 \pm 0.05$ & $0.29 \pm 0.05$ & $0.27 \pm 0.08$ \\
H7A & $2.01 \pm 0.05$ & $0.23 \pm 0.05$ & $0.22 \pm 0.08$ \\
H14A/H15A & $1.94 \pm 0.06$ & $0.26 \pm 0.06$ & $0.22 \pm 0.08$ \\
H51A & $3.03 \pm 0.07$ & $0.38 \pm 0.07$ & $0.41 \pm 0.09$ \\
H139A & $1.99 \pm 0.05$ & $0.26 \pm 0.05$ & $0.22 \pm 0.08$ \\
H155A & $2.14 \pm 0.06$ & $0.33 \pm 0.06$ & $0.30 \pm 0.07$ \\
H167A & $2.78 \pm 0.06$ & $0.38 \pm 0.06$ & $0.44 \pm 0.08$ \\
H187A & $1.51 \pm 0.07$ & $0.17 \pm 0.05$ & $0.18 \pm 0.09$ \\
H200A & $1.68 \pm 0.06$ & $0.22 \pm 0.05$ & $0.20 \pm 0.08$ \\
H209A & $2.14 \pm 0.05$ & $0.31 \pm 0.05$ & $0.33 \pm 0.08$ \\
\hline
\end{tabular}

expected for hexacoordinate hemeproteins (13). The ligand switch process, clearly seen for the proximal side of the heme, may thus also occur on the distal side of the heme, and might hamper unequivocal identification of the distal ligand. We cannot rule out the possibility that the distal ligand coordinating the heme iron (as seen by XANES) may not come from a single His, but from an ensemble of histidines, which may interchange in heme coordination. Furthermore, the replacing residue can also be different from a His, as observed for the heme-binding PAS (Per-Arnt-Sim) domain YybT (40), which displays UV-Vis spectra strikingly similar to other His-ligated hemoproteins but has no histidine (or cysteine) in the amino acidic sequence. However, even though other residues can be possible axial ligands of the heme iron (33), including the Nterminal amino-group $(22,34)$, the corresponding XANES spectra to be compared to the DNR one are not currently available.

In conclusion, we propose that, upon NO binding, dissociation from the heme iron of both His187 and an unidentified residue(s) is crucial to trigger the conformational transition (OFF to ON) required for DNR activation; these residues are available for novel interactions (such as salt bridges and/or $\mathrm{H}$-bonds, to date not yet identified) that allow the protein to dramatically rearrange for DNA binding. This mechanism necessarily implies peculiar protein flexibility as an intrinsic property of DNR, as strongly suggested by the novel data reported in the present study. Moreover, the effect obtained by mutating the His residues in DNR suggests that this reg- ulator behaves as a gas sensor heme-binding protein. The general idea that, among hemeproteins, polypeptide flexibility may indeed distinguish heme-based gas sensors from canonical hemeprotein is supported by results on synthetic heme-peptides complexes (6), on heme-responsive proteins $(19,21,26,37,50)$ and on the CO sensor protein CooA from Rhodospirillium rubrum (42).

Structural flexibility is also a common feature of other members of the CRP-FNR family that do not use heme as sensory module $(4,10,29,31,39,46)$. It is therefore tempting to speculate that protein flexibility may be the long sought structural feature essential to explain the evolutionary success and adaptability of the CRP-FNR class of transcriptional regulators.

\section{Materials and Methods}

\section{Expression and purification of heme-containing DNR}

The pET-DNR vector was cotransformed into E. coli BL21(DE3) strain with the pHPEX3 vector (13); protein expression was induced and performed accordingly.

The soluble cell extract was fractionated using 10\% ammonium sulfate precipitation to remove the excess of free heme; DNR protein was then enriched after Q-Sepharose Fast Flow and Heparin columns (Amersham) both equilibrated with $20 \mathrm{mM}$ Tris pH 7.2 and eluted with an $\mathrm{NaCl}$ gradient. DNR-containing fractions were then pooled and spectra collected.

\section{Mutagenesis and protein preparation}

The recombinant wild-type apo-DNR and the hemecontaining DNR were prepared as reported in $(12,13)$. Sitedirected mutagenesis was done as previously reported using pACY-DNR (5) and pET28-DNRHIS (13) as a template, and confirmed by DNA sequencing. The two different constructs were used for the $\beta$-galactosidase assay and protein expression, respectively. Expression and purification of the mutant proteins were carried out as described in (12) for the wildtype.

\section{XAFS spectroscopy}

The Fe K-edge XAFS spectra of all derivatives of DNR have been collected in fluorescence mode at ESRF-BM30B,
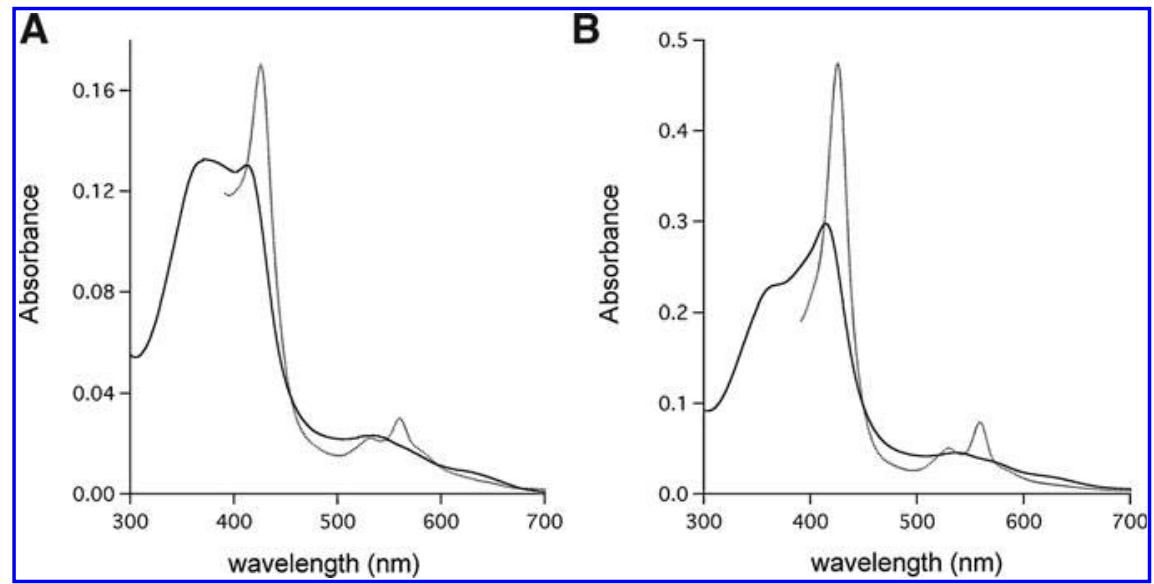

FIG. 8. Spectral properties of DNR double histidine mutants. Optical absorption spectra of the $\mathrm{Fe}^{3+}$ (black line) and $\mathrm{Fe}^{2+}$ (dotted line) derivatives of (A) H167A/H187A and (B) H139A/ H187A DNR proteins. The spectrum of the $\mathrm{Fe}^{3+}$ derivatives is also shown below $380 \mathrm{~nm}$ to highlight the peculiar peak present at $370 \mathrm{~nm}$ in H167A/ H187A (A) that is reminiscent of a heme with weakly coordinated or absent axial ligands. 
Grenoble, by using a 30-elements ultra-pure Ge detector. The spectra were calibrated by assigning the first inflection point of the Fe foil spectrum to $7112 \mathrm{eV}$. The energy stability of each spectrum was carefully assessed by checking the position of a glitch in the $\mathrm{I}_{0}$ at $7220 \mathrm{eV}$. The ferric DNR solution $(1.6 \mathrm{mM}$ of protein in $100 \mathrm{mM}$ phosphate buffer, $250 \mathrm{mM} \mathrm{NaCl}, \mathrm{pH}$, and glycerol 20\%) was reduced, if indicated, by addition of $20 \mathrm{mM}$ sodium dithionite. The NO-bound form has been obtained by fluxing with NO gas the chemically reduced sample. The tetra-coordinate $\mathrm{Fe}(\mathrm{II})$-protoheme model system was obtained by dissolving hemin in $10 \%$ sodium dodecyl sulfate and reducing it by an excess of sodium dithionite.

\section{In vivo B-galactosidase assay}

The mutated pACY-DNR plasmid together with the pRSNOR reporter vector (5) were transformed, for each mutant construct, into the TOP10 E. coli strain (Invitrogen). Bacterial growth and $\beta$-galactosidase assay were carried out as previously reported (5).

\section{Optical absorption and CD spectra}

The ferric derivative was handled anaerobically to obtain the ferrous derivative by adding $1 \mathrm{~m} M$ of sodium dithionite. The ferrous protein was incubated under anaerobic conditions with a saturated atmosphere of $\mathrm{CO}$ gas or with $100 \mu \mathrm{l}$ of a $2 \mathrm{mM}$ NO solution $\left(20^{\circ} \mathrm{C}\right.$ and $\left.\mathrm{pH} 7,5\right)$ to obtain the corresponding derivative. Spectra of the heme-reconstituted DNR species (4-7 $\mu M$ solution) were recorded on a Jasco V650 spectrophotometer, using gas-tight tonometer containing a 1$\mathrm{cm}$ quartz cuvette.

CD spectra were measured using a Jasco CD spectrometer at $20^{\circ} \mathrm{C}$ using a $1-\mathrm{cm}$ quartz cuvette (Hellma); heme concentration was determined using the pyridine hemochromogen assay. Data were smoothed using the Savitzky-Golay method (43) with a convolution width of 9.

\section{Kinetic measurements}

For laser photolysis, the ferrous-CO bound protein (a $10 \mu \mathrm{M}$ solution for wild type and His mutants, in $40 \mathrm{mM}$ sodium phosphate $\mathrm{pH} 7.5,300 \mathrm{mM} \mathrm{NaCl}$ ) was prepared by adding anaerobically $\mathrm{CO}$ solution (final $\mathrm{CO}$ concentration $=1 \mathrm{mM}$ and $0.7 \mathrm{mM}$ at $25^{\circ} \mathrm{C}$ ) to the reduced protein (see above) in a gas-tight tonometer for fluorescence assays.

The instrument used for photolysis experiments has been described in detail elsewhere (2).

The time course of $\mathrm{CO}$ re-binding after laser photolysis is followed at single wavelength (436 and $406 \mathrm{~nm}$ ). The traces were fitted as a sum of three-exponentials (see also Supplementary Fig. S2) by using the nonlinear least squares routines provided by the Matlab package (The MathWorks ${ }^{\mathrm{TM}}$ ).

All the stopped flow experiments were carried out anaerobically according to (13). The concentration of the samples is always given a.m., using a 1:1 dilution in the symmetric mixing apparatus. Briefly, ferrous DNR (see above) was mixed with two different $\mathrm{NO}$ solutions (88 and $175 \mu \mathrm{M}$ NO a.m., in $50 \mathrm{mM}$ sodium phosphate $\mathrm{pH} 7.5$, $300 \mathrm{mM} \mathrm{NaCl}, 10 \mathrm{mM}$ glucose at $20^{\circ} \mathrm{C}$ ) in the stopped flow apparatus. To prevent oxidation of DNR before the stopped flow experiments, catalytic amounts of catalase $(390 \mathrm{U} / \mathrm{ml})$ and glucose oxidase $(6 \mathrm{U} / \mathrm{ml})$ were also added to all the syringes. Dithionite was absent from the NO-containing syringes.

The kinetic rates were obtained by fitting the time courses at $427 \mathrm{~nm}$ with a two-exponentials equation.

The NO dissociation rate constant has been determined for all DNR mutants according to (13). The analysis of the kinetics was always carried out with the IgorPro program (Wavemetrics)

\section{Acknowledgments}

Funds from the Ministero della Università of Italy (RBRN07BMCT and 20094BJ9RT), from the University of Rome La Sapienza, and from Fondazione Italiana Fibrosi Cistica to F.C. are gratefully acknowledged. We acknowledge the European Synchrotron Radiation Facility for provision of synchrotron radiation facilities and the staff of BM30B for the helpful support. Maurizio Brunori is gratefully acknowledged for fruitful discussion on experiments and for critical reading of the article.

\section{Author Disclosure Statement}

The authors have no financial conflict of interest.

\section{References}

1. Arai H, Igarashi $\mathrm{Y}$, and Kodama T. Expression of the nir and nor genes for denitrification of Pseudomonas aeruginosa requires a novel CRP/FNR-related transcriptional regulator, DNR, in addition to ANR. FEBS Lett 371: 73-76, 1995.

2. Arcovito A, Gianni S, Brunori M, Travaglini-Allocatelli C, and Bellelli A. Fast coordination changes in cytochrome c do not necessarily imply folding. I Biol Chem 276: 41073-41078, 2001.

3. Arcovito A, Moschetti T, D'Angelo P, Mancini G, Vallone B, Brunori $\mathrm{M}$, and Della Longa S. An X-ray diffraction and Xray absorption spectroscopy joint study of neuroglobin. $\underline{\text { Arch }}$ Biochem Biophys 475: 7-13, 2008.

4. Borjigin M, Li H, Lanz ND, Kerby RL, Roberts GP, and Poulos TL. Structure-based hypothesis on the activation of the CO-sensing transcription factor CooA. Acta Crystallogr D Biol Crystallogr 63: 282-287, 2007.

5. Castiglione N, Rinaldo S, Giardina G, and Cutruzzolà F. The transcription factor DNR from Pseudomonas aeruginosa specifically requires nitric oxide and haem for the activation of a target promoter in Escherichia coli. Microbiology 155: 28382844, 2009.

6. Cowley AB, Kennedy ML, Silchenko S, Lukat-Rodgers GS, Rodgers KR, and Benson DR. Insight into heme protein redox potential control and functional aspects of six-coordinate ligand-sensing heme proteins from studies of synthetic heme peptides. Inorg Chem 45: 9985-10001, 2006.

7. Della Longa S, Arcovito A, Vallone B, Congiu Castellano A, Soldo Y, and Hazemann JL. Polarized X-ray absorption spectroscopy (P-XAS) of photolyzed carbonmonoxymyoglobin. L Synchr Rad 6: 1138-1147, 1999.

8. Della Longa S, Bianconi A, Palladino L, Simonelli B, Congiu Castellano A, Borghi E, Barteri M, Beltramini M, Rocco GP, Salvato B, Bubacco L, Magliozzo RS, and Peisach J. An x-ray absorption near edge structure spectroscopy study of metal coordination in $\mathrm{Co}(\mathrm{II})$-substituted Carcinus maenas hemocyanin. Biophys I 65: 2680-2691, 1993.

9. Dufour YS, Kiley PJ, and Donohue TJ. Reconstruction of the core and extended regulons of global transcription factors. PLoS Genet 6: e1001027, 2010. 
10. Eiting M, Hagelüken G, Schubert WD, and Heinz DW. The mutation G145S in PrfA, a key virulence regulator of Listeria monocytogenes, increases DNA-binding affinity by stabilizing the HTH motif. Mol Microbiol 56: 433-446, 2005.

11. Gallagher D, Smith N, Kim S, Robinson H, and Reddy P. Profound asymmetry in the structure of the cAMP-free cAMP Receptor Protein (CRP) from Mycobacterium tuberculosis. L Biol Chem 284: 8228-8232, 2009.

12. Giardina G, Rinaldo S, Castiglione N, Caruso M, and Cutruzzolà $\mathrm{F}$. A dramatic conformational rearrangement is necessary for the activation of DNR from Pseudomonas aeruginosa. Crystal structure of wild-type DNR. Proteins 77: 174-180, 2009.

13. Giardina G, Rinaldo S, Johnson KA, Di Matteo A, Brunori M, and Cutruzzolà F. NO sensing in Pseudomonas aeruginosa: structure of the transcriptional regulator DNR. $[\mathrm{Mol}$ Biol 378: 1002-1015, 2008.

14. Gibson QH, Olson JS, McKinnie RE, and Rohlfs RJ. A kinetic description of ligand binding to sperm whale myoglobin. I Biol Chem 261: 10228-10239, 1986.

15. Gilles-Gonzalez MA and Gonzalez G. Heme-based sensors: defining characteristics, recent developments, and regulatory hypotheses. I Inorg Biochem 99: 1-22, 2005.

16. Gomelsky M. Cyclic-di-GMP-binding CRP-like protein: a spectacular new role for a veteran signal transduction actor. J Bacteriol 191: 6785-6787, 2009.

17. Green J, Scott C, and Guest JR. Functional versatility in the CRP-FNR superfamily of transcription factors: FNR and FLP. Adv Microb Physiol 44: 1-34, 2001.

18. Hassett DJ, Cuppoletti J, Trapnell B, Lymar SV, Rowe JJ, Yoon SS, Hilliard GM, Parvatiyar K, Kamani MC, Wozniak DJ, Hwang SH, McDermott TR, and Ochsner UA. Anaerobic metabolism and quorum sensing by Pseudomonas aeruginosa biofilms in chronically infected cystic fibrosis airways: rethinking antibiotic treatment strategies and drug targets. Adv Drug Deliv Rev 54: 1425-1443, 2002.

19. Hayasaka K, Kitanishi K, Igarashi J, and Shimizu T. Hemebinding characteristics of the isolated PAS-B domain of mouse Per2, a transcriptional regulatory factor associated with circadian rhythms. Biochim Biophys Acta 1814: 326-333, 2011.

20. Hsu MC and Wood RW. Origin of the heme Cotton effects in myoglobin and hemoglobin. IAm Chem Soc 93: 3515-3525, 1971.

21. Igarashi J, Murase M, lizuka A, Pichierri F, Martinkova M, and Shimizu T. Elucidation of the heme binding site of heme-regulated eukaryotic initiation factor 2alpha kinase and the role of the regulatory motif in heme sensing by spectroscopic and catalytic studies of mutant proteins. L Biol Chem 283: 18782-18791, 2008.

22. Inagaki S, Masuda C, Akaishi T, Nakajima H, Yoshioka S, Ohta T, Pal B, Kitagawa T, and Aono S. Spectroscopic and redox properties of a CooA homologue from Carboxydothermus hydrogenoformans. I Biol Chem 280: 3269-3274, 2005.

23. Ishitsuka Y, Araki Y, Tanaka A, Igarashi J, Ito O, and Shimizu T. Arg97 at the heme-distal side of the isolated hemebound PAS domain of a heme-based oxygen sensor from Escherichia coli (Ec DOS) plays critical roles in autoxidation and binding to gases, particularly O2. Biochemistry 47: 88748884, 2008.

24. Kannan N, Wu J, Anand GS, Yooseph S, Neuwald AF, Venter JC, and Taylor SS. Evolution of allostery in the cyclic nucleotide binding module. Genome Biol 8: R264, 2007.
25. Kharitonov VG, Sharma VS, Magde D, and Koesling D. Kinetics of nitric oxide dissociation from five- and six-coordinate nitrosyl hemes and heme proteins, including soluble guanylate cyclase. Biochemistry 36: 6814-6818, 1997.

26. Kitanishi K, Igarashi J, Hayasaka K, Hikage N, Saiful I, Yamauchi S, Uchida T, Ishimori K, and Shimizu T. Hemebinding characteristics of the isolated PAS-A domain of mouse Per2, a transcriptional regulatory factor associated with circadian rhythms. Biochemistry 47: 6157-6168, 2008.

27. Körner H, Sofia HJ, and Zumft WG. Phylogeny of the bacterial superfamily of Crp-Fnr transcription regulators: exploiting the metabolic spectrum by controlling alternative gene programs. FEMS Microbiol Rev 27: 559-592, 2003.

28. Lawson C, Swigon D, Murakami K, Darst S, Berman H, and Ebright R. Catabolite activator protein: DNA binding and transcription activation. Curr Opin Struct Biol 14: 10-20, 2004.

29. Lee AJ, Clark RW, Youn H, Ponter S, and Burstyn JN. Guanidine hydrochloride-induced unfolding of the three heme coordination states of the CO-sensing transcription factor, CooA. Biochemistry 48: 6585-6597, 2009.

30. Lee YY, Shearer N, and Spiro S. Transcription factor NNR from Paracoccus denitrificans is a sensor of both nitric oxide and oxygen: isolation of $\mathrm{nnr}^{*}$ alleles encoding effectorindependent proteins and evidence for a haem-based sensing mechanism. Microbiology 152: 1461-1470, 2006.

31. Levy C, Pike K, Heyes DJ, Joyce MG, Gabor K, Smidt H, van der Oost J, and Leys D. Molecular basis of halorespiration control by CprK, a CRP-FNR type transcriptional regulator. Mol Microbiol 70: 151-167, 2008.

32. Li B, Wing H, Lee $\mathrm{D}, \mathrm{Wu} \mathrm{H}$, and Busby S. Transcription activation by Escherichia coli FNR protein: similarities to, and differences from, the CRP paradigm. Nucleic Acids Res 26: 2075-2081, 1998.

33. Li T, Bonkovsky H, and Guo J. Structural analysis of heme proteins: implications for design and prediction. BMC Struct Biol 11-13, 2011.

34. Martinez SE, Huang D, Szczepaniak A, Cramer WA, and Smith JL. Crystal structure of chloroplast cytochrome f reveals a novel cytochrome fold and unexpected heme ligation. Structure 2: 95-105, 1994.

35. McKay DB and Steitz TA. Structure of catabolite gene activator protein at 2.9 A resolution suggests binding to lefthanded B-DNA. Nature 290: 744-749, 1981.

36. Miller JH. Experiments in Molecular Genetics. Cold Spring Harbor, NY: Cold Spring Harbor Laboratory Press, 1972, pp. 352-355.

37. Pardee $\mathrm{K}, \mathrm{Xu} \mathrm{X}$, Reinking J, Schuetz A, Dong A, Liu S, Zhang R, Tiefenbach J, Lajoie G, Plotnikov A, Botchkarev A, Krause $\mathrm{H}$, and Edwards A. The structural basis of gasresponsive transcription by the human nuclear hormone receptor REV-ERBbeta. PLoS Biol 7: e43, 2009.

38. Parkinson G, Gunasekera A, Vojtechovsky J, Zhang X, Kunkel TA, Berman H, and Ebright RH. Aromatic hydrogen bond in sequence-specific protein DNA recognition. Nat Struct Biol 3: 837-841, 1996.

39. Popovych N, Tzeng SR, Tonelli M, Ebright RH, and Kalodimos CG. Structural basis for cAMP-mediated allosteric control of the catabolite activator protein. Proc Natl Acad Sci U S A 106: 6927-6932, 2009.

40. Rao F, Ji Q, Soehano I, and Liang Z. Unusual heme-binding PAS domain from YybT family proteins. LBacteriol 193: 1543-1551, 2011.

41. Rinaldo S, Giardina G, Brunori M, and Cutruzzola F. N-oxide sensing in Pseudomonas aeruginosa: expression and preliminary 
characterization of DNR, an FNR-CRP type transcriptional regulator. Biochem Soc Trans 33: 184-186, 2005.

42. Roberts GP, Kerby RL, Youn H, and Conrad M. CooA, a paradigm for gas sensing regulatory proteins. IInorg Biochem 99: 280-292, 2005.

43. Savitzky A and Golay MJE. Smoothing and Differentiation of Data by Simplified Least Squares Procedures. Anal Chem 36: 1627-1639, 1964.

44. Smagghe BJ, Sarath G, Ross E, Hilbert JL, and Hargrove MS. Slow ligand binding kinetics dominate ferrous hexacoordinate hemoglobin reactivities and reveal differences between plants and other species. Biochemistry 45: 561-570, 2006.

45. Tao F, He YW, Wu DH, Swarup S, and Zhang LH. The cyclic nucleotide monophosphate domain of Xanthomonas campestris global regulator Clp defines a new class of cyclic di-GMP effectors. J Bacteriol 192: 1020-1029, 2010.

46. Tzeng SR and Kalodimos CG. Dynamic activation of an allosteric regulatory protein. Nature 462: 368-372, 2009.

47. Van Alst NE, Picardo KF, Iglewski BH, and Haidaris CG. Nitrate sensing and metabolism modulate motility, biofilm formation, and virulence in Pseudomonas aeruginosa. Infect Immun 75: 3780-3790, 2007.

48. Vollack KU and Zumft WG. Nitric oxide signaling and transcriptional control of denitrification genes in Pseudomonas stutzeri. I Bacteriol 183: 2516-2526, 2001.

49. Won H, Lee Y, Lee S, and Lee B. Structural overview on the allosteric activation of cyclic AMP receptor protein. Biochim Biophys Acta 1794: 1299-1308, 2009.

50. Yang J, Ishimori K, and O'Brian MR. Two heme binding sites are involved in the regulated degradation of the bacterial iron response regulator (Irr) protein. I Biol Chem 280: 76717676, 2005.

51. Yano J and Yachandra VK. X-ray absorption spectroscopy. Photosynth Res 102: 241-254, 2009.

52. Yoon SS, Hennigan RF, Hilliard GM, Ochsner UA, Parvatiyar K, Kamani MC, Allen HL, DeKievit TR, Gardner PR, Schwab U, Rowe JJ, Iglewski BH, McDermott TR, Mason RP, Wozniak DJ, Hancock RE, Parsek MR, Noah TL, Boucher RC, and Hassett DJ. Pseudomonas aeruginosa anaerobic res- piration in biofilms: relationships to cystic fibrosis pathogenesis. Dev Cell 3: 593-603, 2002.

Address correspondence to: Prof. Francesca Cutruzzolà

Dipartimento di Scienze Biochimiche "A. Rossi Fanelli" Sapienza Università di Roma

P.le A.Moro 5

00185 Rome

Italy

E-mail: francesca.cutruzzola@uniroma1.it

Date of first submission to ARS Central, August 10, 2011; date of final revised submission, March 16, 2012; date of acceptance, March 18, 2012.

$\quad$ Abbreviations Used
a.m. $=$ after mixing
$\mathrm{CD}=$ circular dichroism
$\mathrm{CF}=$ cystic fibrosis
$\mathrm{CO}=$ carbon monoxide
$\mathrm{CRP}-\mathrm{FNR}=$ cAMP receptor protein $/$ fumarate and nitrate
reductase regulator
$\mathrm{DNR}=$ dissimilatory nitrate respiration regulator
$\mathrm{HS}=$ high-spin
$\mathrm{HTH}=$ helix-turn-helix
$\mathrm{LS}=$ low-spin
$\mathrm{MbNO}=$ nitrosyl-myoglobin
$\mathrm{Ngb}=$ neuroglobin
$\mathrm{NO}=$ nitric oxide
$\mathrm{TPP}=$ Fe(II)-tetraphenylporphyrin
$\mathrm{UV}-\mathrm{Vis}=$ ultraviolet-visible
$\mathrm{XAFS}=$ X-ray absorption fine structure
$\mathrm{XANES}=$ X-ray absorption near edge structure


This article has been cited by:

1. Andrew M. Stern, Jun ZhuAn Introduction to Nitric Oxide Sensing and Response in Bacteria 87, 187-220. [CrossRef] 